\title{
HUBUNGAN ANTARA INTERAKSI SOSIAL TEMAN SEBAYA DENGAN PENERIMAAN SOSIAL SISWA KELAS XI IPA SMA NEGERI 09 KOTA BENGKULU
}

\author{
Maelan Tri Yuliani, Syahriman \\ Prodi Bimbingan dan Konseling Fakultas Keguruan dan Ilmu Pendidikan \\ Universitas Bengkulu \\ Maelan.tri03@gmail.com,syahriman@unib.ac.id,ritasinthia@unib.ac.id
}

\begin{abstract}
ABSTRAK
Penelitian ini bertujuan untuk mengetahui hubungan antara interaksi sosial teman sebaya dengan penerimaan sosial pada siswa kelas XI di SMA Negeri 9 Kota Bengkulu. Penelitian ini menggunakan pendekatan kuantitatif dengan jenis korelasional. Subjek dalam penelitian ini adalah siswa kelas XI dengan jumlah siswa sebanyak 76 orang. Teknik pengambilan sampel dalam penelitian ini ialah dengan menggunakan total sampling. Alat pengumpulan data menggunakan skala interaksi sosial teman sebaya dan skala penerimaan sosial. Uji validitas instrumen menggunakan product moment dari Pearson, sedangkan reliabilitas menggunakan Alpha cronbach dengan nilai koefisien 0,753 pada interaksi sosial teman sebaya dan 0,908 pada penerimaan sosial. Analisis data untuk menguji hipotesis dengan menggunakan teknik korelasi product moment dari Pearson. Hasil penelitian ini menunjukkan bahwa terdapat hubungan yang positif dan signifikan antara interaksi sosial teman sebaya dengan penerimaan sosial pada siswa kelas XI di SMA Negeri 09 Kota Bengkulu. Hal ini ditunjukkan dengan koefisien korelasi (rxy) sebesar 0,91 atau lebih dari 0,05 dan $\mathrm{p}=0,000(\mathrm{p}<0,05)$ yang berarti hipotesis alternatif (Ha) diterima. Besarnya koefisien korelasi bersifat positif, artinya semakin tinggi tingkat interaksi sosial teman sebaya siswa, semakin tinggi pula tingkat penerimaan sosial, sebaliknya, semakin rendah tingkat interaksi sosial teman sebaya siswa, semakin rendah pula tingkat penerimaan sosial.
\end{abstract}

Kata kunci : interaksi sosial teman sebaya, penerimaan sosial

\section{RELATIONSHIP BETWEEN SOCIAL INTERACTION OF FRIENDS AND SOCIAL ACCEPTANCE OF STUDENTS IN CLASS XI IPA SMA NEGERI 09 BENGKULU}

This reasearch aimed to determine the relationship between social interactions of peer friends to social acceptance on class XI students at SMA Negeri 9 Bengkulu City. This research used a quantitative approach with a correlational type.The subjects of this reseacrh was 76 students in class XI. The sampling technique of this research was by using sampling total. The Data collection technique by using peer friends social interaction scale and social acceptance scale. The validity test by using Pearson's product moment, mean while the reliability test was by using Alpha Cronbach's with a coefficient value was 0.753 for peer friend interaction and 0.908 for social acceptance. For analyzing data, the research used Pearson's product moment correlation technique. This research was done by shawing that positively and significantly there was coreltion between social interaction of peer friend on class XI student at SMA Negeri 09 Bengkulu City. It was by shawn by the coefficient correlation (rxy) was 0.249 or more than 0.05 and $\mathrm{p}=0.000(\mathrm{p}<0.05)$ which means that the alternative hypothesis $(\mathrm{Ha})$ was accepted. The value of the coefficient correlation was positive, means that the higher level of social interaction of peer friends, so the level of social acceptance is higher too. Otherwise the lower level of social interaction of peer friends, so the level of social acceptance is lower too.

Keywords : social interaction of peers friends, social acceptance 


\section{Pendahuluan}

Masa remaja merupakan masa yang sangat penting dalam proses perkembangan. Perkembangan pada masa remaja seharusnya mendapatkan perhatian dari berbagai pihak, terutama dari lingkungan terdekatnya (Hurlock,2002: 201). Salah satu bagian terpenting dari perkembangan remaja adalah perkembangan dalam kehidupan sosial. Memang perkembangan fisik tidak dapat dilepaskan, tetapi kebanyakan kasus remaja terjadi dikarenakan kurang sempurnanya proses perkembangan sosialnya.

Hal yang tak kalah penting dalam masa remaja adalah perubahan sosial remaja itu sendiri. Syamsu Yusuf (2011: 122) menyatakan, perkembangan sosial merupakan pencapaian kematangan dalam hubungan sosial dan dimaknakan sebagai proses belajar untuk menyesuaikan diri terhadap norma - norma kelompok, oral dan tradisi, melebur diri menjadi satu kesatuan dan saling berkomunikasi serta bekerjasama. Setiap individu melakukan interaksi sosial dengan linkungannya. Remaja dalam interaksi sosial tersebut berusaha melakukan penyesuaian terhadap lingkunganya. Remaja melakukan penyesuaian gaya bicara, gaya berpenampilan bahkan melakukan imitasi kepribadian terhadap teman sebaya di lingkungan sekitarnya. Remaja lebih sering berada di luar rumah bersama dengan temanteman sebaya sebagai kelompok, maka dapatlah dipahami bahwa pengaruh teman-teman sebaya pada sikap, pembicaraan, minat, penampilan dan perilaku lebih besar dari pada pengaruh keluarga. Anak belajar mengenal dirinya sendiri dan kedudukannya dalam kelompok melalui hubungan interpersonal dengan teman sebaya.

Pada perkembangan kehidupan sosial, remaja memiliki berbagai macam tugas perkembangan yang harus dilalui agar kehidupan sosial remaja berjalan dengan baik di masa yang akan datang. Salah satu tugas perkembangan sosial remaja adalah membina hubungan sosial dengan teman sebaya dan orang dewasa selain guru dan orang tua (Syamsu Yusuf, 2011: 66). Remaja yang telah menjalankan tugas perkembangannya dengan baik mampu berinteraksi dengan teman sebayanya dan diterima dalam kelompok pertemanan. Hal seperti ini tidak lepas dari peran keluarga dan lingkungannya. Remaja yang mendapatkan kasih sayang orang tua, pendidikan dasar keagamaan dan pengawasan hubungan bermasyarakat kerap tidak mengalami kesulitan dalam interaksi dengan teman sebayanya. Namun, masih banyak remaja yang mengalami kendala dalam interaksinya dengan teman sebaya sehingga menyebabkan penolakan hubungan oleh kelompok teman sebayanya. 
Menurut Bimo Walgito (2003: 57) interaksi sosial adalah hubungan antara individu satu dengan individu yang lain, individu satu dapat mempengaruhi individu yang lain atau sebaliknya, jadi terdapat adanya hubungan yang saling timbal balik.

Gillin dan Gillin dalam Soejono Soekanto (2000: 67) interaksi sosial merupakan hubungan sosial yang dinamis, menyangkut hubungan antara individu, antara kelompok, maupun antara individu dengan kelompok.

Interaksi sosial adalah kunci dari semua kehidupan sosial oleh karena itu tanpa adanya interaksi sosial tidak akan mungkin ada kehidupan bersama. Interaksi sosial dimaksudkan sebagai pengaruh timbal balik antar individu dengan golongan didalam usaha mereka untuk memecahkan persoalan yang diharapkan dan dalam usaha mereka untuk mencapai tujuannya (Abu Ahmadi, 2004: 100).

Menurut Slamet Santosa (2004: 79) teman sebaya atau peer group adalah kelompok usia sebaya yang anggotanya mampu berkomunikasi dan berinteraksi dengan baik. Hal-hal yang dilakukan oleh anak-anak usia tersebut adalah hal-hal yang menyenangkan saja. Selain itu, Umar Tirtarahrdja (1995: 181) mengungkapkan bahwa kelompok teman sebaya adalah suatu kelompok yang terdiri dari orang-orang usianya bersamaan, antara lain kelompok bermain pada usia anak-anak, kelompok monoseksual yang beranggotakan anak-anak satu jenis kelamin saja, atau gang yaitu kelompok anak-anak nakal.

Chaplin (1995: 50) penerimaan sosial adalah pengakuan dan penghargaan terhadap nilai-nilai individu. Individu yang mendapatkan penerimaan sosial akan merasa mendapatkan pengakuan dan penghargaan dari individu lain atau kelompok secara utuh.

Penerimaan sosial juga berarti dipilih sebagai teman untuk suatu aktifitas dalam kelompok dimana seseorang menjadi anggota. Ini merupakan indeks keberhasilan yang digunakan seseorang untuk berperan dalam kelompok sosial dan menunjukkan derajat rasa suka anggota kelompok yang lain untuk bekerja sama atau bermain dengannya (Hurlock, 2002: 155).

Pengabaian dan penolakan dari teman sebaya juga dapat mengakibatkan para remaja merasa kesepian dan timbul rasa permusuhan yang selanjutnya berhubungan dengan kesehatan mental individu dan masalah kriminal (Santrock, 2003: 220).

Berdasarkan uraian diatas maka dapat ditarik suatu kesimpulan bahwa ada dampak positif maupun negarif yang ditimbulkan oleh penerimaan dan penolakan sosial. Dampak positif dari penerimaan sosial bagi individu antara lain rasa senang dan aman, diakui orang lain, memiliki kesempatan atau peluang yang lebih besar dalam mengembangkan 
keterampilan, bebas secara mental saling menghargai tradisi. Sedangkan dampak negatif dari penolakan sosial antara lain menimbulkan rasa sedih dan permusuhan, ruang gerak terbatas, suka memaksakan diri dan bersikap berlebihan untuk memperoleh perhatian.

Untuk mengetahui tingkat interaksi sosial dengan penerimaan sosial siswa, peran guru bimbingan dan konseling harus sangat berperan aktif dalam mengawasi siswa. Maka dari itu guru bimbingan dan konseling harus rutin memberikan layanan kepada siswa.

Hasil observasi yang dilakukan peneliti pada saat magang II di SMA Negeri 09 Kota Bengkulu terlihat bahwa beberapa siswa yang sering berkelahi, beradu mulut antar sesama teman baik di kelas maupun di luar kelas. Melihat dari fenomena yang telah diuraikan maka penulis tertarik untuk meneliti hal tersebut dan mengambil judul "Hubungan antara interaksi sosial dengan penerimaan sosial siswa kelas XI IPA SMA Negeri 09 Kota Bengkulu”.

\section{Metode Penelitian}

Metode yang digunakan dalam penelitian ini menggunakan desain deskripsi kuantitatif, dengan teknik korelasi. Populasi yang digunakan pada penelitian ini adalah siswa kelas XI IPA SMA Negeri 09 Kota Bengkulu yang berjumlah 76 siswa. Teknik pengambilan sampel yaitu dengan total sampling. Total sampling adalah teknik pengambilan sampel dimana jumlah sampel sama dengan populasi (Sugiyono,2007: 62) Sampel dalam penelitian ini terbagi menjadi dua yaitu sampel uji coba dan sampel penelitian. Sampel uji coba yang digunakan dalam penelitian ini yaitu satu kelas sebanyak 24 siswa. Sampel penelitian yang digunakan yaitu tiga kelas sebanyak 76 siswa.

Teknik pengumpulan data yang digunakan dalam penelitian ini adalah angket. Angket adalah suatu daftar yang berisi pertanyaan-pertanyaan yang harus dijawab atau dikerjakan oleh responden atau orang/anak yang ingin diselidiki (Walgito, 2010: 72). Kedua angket tersebut menggunakan metode Skala, dengan menyediakan empat alternatif jawaban, yaitu Sangat sesuai (SS), Sesuai (S), Tidak sesuai (TS), dan Sangat tidak sesuai (STS) dan terdiri dari pernyataan favorable (pernyataan positif)dan unfavorable (pernyataan negatif) terhadap interaksi sosial teman sebaya dengan penerimaan sosial. Sebelum angket diberikan kepada sampel penelitian angket tersebut di uji validitas, daya pembeda dan reliabilitas. Uji validitas dilakukan oleh dua orang ahli. Dari hasil uji daya pembeda pada variabel interaksi sosial yang berjumlah 40 pernyataan terdapat 7 item yang tidak memenuhi syarat daya pembeda sedangkan pada variabel penerimaan sosial yang berjumlah 48 item terdapat 10 item yang tidak memenuhi syarat daya pembeda. Hasil uji reliabilitas pada variabel interaksi sosial 
diperoleh nilai Cronbach's Alpha $=0,753$ dan pada variabel penerimaan sosial diperoleh nilai Cronbach's Alpha $=0,908$. Data yang diperoleh dari sampel penelitian kemudian dianalisis menggunakan uji normalitas, uji linieritas dan uji hipotesis menggunakan pearson product moment.

\section{Hasil dan Pembahasan}

Deskripsi data pada bagian ini adalah deskripsi tentang masing-masing variabel, yang diteliti yaitu interaksi sosial (Y) dengan penerimaan sosial (X). Deskripsi tentang interaksi sosial dan penerimaan sosial diperoleh dari hasil penyebaran kuesioner ke sejumlah responden yang menjadi sampel penelitian.

Berdasarkan skor yang diperoleh, didapatkan gambaran umum yang dihitung berdasarkan skor ideal. Deskripsi data interaksi sosial teman sebaya siswa kelas XI IPA SMA Negeri 09 Kota Bengkulu pada Tabel 1.

Tabel 1

Deskripsi Data Interaksi Sosial

\begin{tabular}{cc}
\hline Jumlah Sampel & $\mathbf{7 6}$ \\
\hline Skor Minimum & 33 \\
\hline Skor Maximum & 132 \\
\hline Rata - rata $(\mu)$ & 82,5 \\
\hline Standar Deviasi $(\sigma)$ & 16.5 \\
\hline
\end{tabular}

Berdasarkan tabel 1 diperoleh gambaran tentang interaksi sosial dengan skor minimum sebesar 33, skor maximum sebesar 132, rata - rata sebesar 82,5, dan standar deviasinya sebesar 16,5. Selanjutnya skor - skor di kategorisasi. Subjek digolongkan dalam tiga kategori interaksi sosial teman sebaya yaitu, tinggi, sedang, rendah.

Tabel 2

Kategorisasi Data Interaksi Sosial

\begin{tabular}{cccc}
\hline Kategori & Rentang Skor & Frekuensi & Persentase (\%) \\
\hline Rendah & $33-66$ & 0 & $0 \%$ \\
\hline Sedang & $67-99$ & 51 & $33 \%$ \\
\hline Tinggi & $100-132$ & 25 & $67 \%$
\end{tabular}

Kuesioner interaksi sosial yang terdiri dari 33 item dengan 4 pilihan jawaban yang bergerak dari 1 sampai 4 , sehingga diperoleh rentang minimum adalah 33x1=33 maximum 
adalah $33 \times 4=132$, sehingga luas jarak sebarannya $132-33=9$. Dengan demikian setiap satuan deviasi standarnya bernilai $\boldsymbol{\sigma}=99 / 6=82,5$ dan mean idealnya adalah 82,5.

Berdasarkan Tabel 2 dapat dilihat bahwa subjek yang memiliki interaksi sosial rendah sebanyak $0 \%$, subjek yang memiliki interaksi sosial sedang $67 \%$ sebanyak, dan subjek yang memiliki interaksi sosial tinggi 33\% sebanyak.

Berdasarkan skor yang diperoleh, didapatkan gambaran umum yang dihitung berdasarkan skor ideal. Deskripsi data penerimaan sosial siswa kelas XI IPA SMA Negeri 09 Kota Bengkulu pada Tabel 3 :

Tabel 3

Deskripsi Data Penerimaan Sosial

\begin{tabular}{cc}
\hline Jumlah Sampel & $\mathbf{7 6}$ \\
\hline Skor Minimum & 38 \\
\hline Skor Maximum & 152 \\
\hline Rata - rata $(\mu)$ & 95 \\
\hline Standar Deviasi $(\sigma)$ & 19 \\
\hline
\end{tabular}

Kuesioner penerimaan sosial yang terdiri dari 38 item dengan 4 pilihan jawaban yang bergerak dari 1 sampai 4, sehingga diperoleh rentang minimum adalah 38x1=38 maximum adalah $33 \times 4=152$, sehingga luas jarak sebarannya $152-38=114$. Dengan demikian setiap satuan deviasi standarnya bernilai $\boldsymbol{\sigma}=114 / 6=19$ dan mean idealnya adalah 95 .

Tabel 4

Kategorisasi Penerimaan Sosial

\begin{tabular}{cccc}
\hline Kategori & Rentang Skor & Frekuensi & Persentase \\
\hline Rendah & $38-76$ & 0 & $0 \%$ \\
\hline Sedang & $77-95$ & 0 & $0 \%$ \\
\hline Tinggi & $96-152$ & 100 & $100 \%$ \\
\hline
\end{tabular}

Berdasarkan Tabel 4 dapat dilihat bahwa subjek yang memiliki penerimaan sosial rendah sebanyak $0 \%$, subjek yang memiliki penerimaan sosial sedang sebanyak $0 \%$, dan subjek yang memiliki penerimaan sosial tinggi sebanyak $100 \%$.

Sebelum menguji hipotesis, terlebih dahulu dilakukan uji prasyarat analisis sebagai syarat sebelum melakukan uji hipotesis penelitian dengan jumlah sampel sebanyak 76 siswa. Uji prasyarat analisis tersebut meliputi uji normalitas dan uji linieritas. Hasil Uji normalitas menunjukkan skor Kolmogorov Smirnov variabel interaksi sosial dengan $\mathrm{p}=0,80(\mathrm{p}>0,05)$ sedangkan skor Kolmogorov Smirnov variabel penerimaan sosial dengan $p=0,86(p>0,05)$ 
yang berarti variabel perilaku memaafkan dan regulasi emosi memiliki distribusi normal. Uji linieritas hubungan antara interaksi sosial menghasilkan lin $=0,263$ dengan penerimaan sosial menghasilkan lin $=0,249$ da dengan nilai signifikasi $0,000(\mathrm{p} 0,05)$ menunjukkan adanya hubungan linier antara variabel interaksi sosial dengan penerimaan sosial. Berdasarkan hasil uji hipotesis menggunakan analisis korelasi pearson product moment, diperoleh koefisien korelasi antara interaksi sosial dengan penerimaan sosial sebesar 0,91 dengan $p=0,000$ $(\mathrm{p}<0,05)$, menunjukan bahwa terdapat hubungan yang signifikansi antara interaksi sosial dengan penerimaan sosial.

Berdasarkan hasil uji hipotesis diperoleh koefisien korelasi 0,000 yang berarti terdapat hubungan positif antara variabel $\mathrm{X}$ dan variabel $\mathrm{Y}$. Hubungan yang positif dapat diartikan bahwa hubungan kedua variabel bersifat searah, bersifat searah artinya jika variabel $\mathrm{X}$ nilainya tinggi, maka variabel $\mathrm{Y}$ akan tinggi juga, dan sebaliknya jika variabel $\mathrm{X}$ nilainya rendah, maka variabel Y rendah juga. Signifikansi pada hasil uji hipotesis ini adalah $0,000(\leq$ $0,05)$.

Berdasarkan hal tersebut hipotesis alternatif (Ha) yang diajukan dalam penelitian ini dapat diterima yaitu ada hubungan positif dan signifikan antara interaksi sosial teman sebaya dengan penerimaan sosial. Artinya, semakin tinggi tingkat interaksi sosial teman sebaya maka semakin tinggi juga tingkat penerimaan sosialnya, begitu pula sebaliknya, semakin rendah tingkat interaksi sosial teman sebaya maka semakin rendah juga tingkat penerimaan sosialnya.

\section{Kesimpulan}

Individu yang memiliki interaksi sosial yang tinggi pada siswa kelas XI IPA di SMA Negeri 09 Kota Bengkulu dapat berinteraksi sosial dengan teman sebayanya secara baik dan positif dalam interaksinya dapat saling menerima keberadaan siswa lain, saling memberikan perhatian dan turut merasakan hal - hal yang dialamai oleh teman sebayanya.

Penerimaan sosial pada kategori tinggi dapat diartikan bahwa siswa kelas XI IPA SMA Negeri 09 Kota Bengkulu memiliki kompetensi yang tinggi, penampilan yang menarik, dan dapat berpartisipasi sesuai peranya dalam kelompok teman sebaya.

Terdapat hubungan positif dan signifikan antara interaksi sosial teman sebaya dengan penerimaan sosial pada siswa kelas XI IPA di SMA Negeri 09 Kota Bengkulu dapat dijabarkan dengan nilai koefisien korelasinya sebesar 0,91. Artinya, semakin tinggi tingkat interaksi sosial teman sebaya maka semakin tinggi pula tingkat penerimaan sosial pada siswa kelas XI IPA di SMA Negeri 09 Kota Bengkulu, demikian juga sebaliknya semakin rendah 
tingkat interaksi sosial teman sebaya maka semakin rendah pula tingkat penerimaan sosial kelas XI IPA di SMA Negeri 09 Kota Bengkulu.

Diharapkan bagi Guru Bimbingan dan Konseling harus mengoptimalkan layanan informasi mengenai interaksi sosial teman sebaya, walaupun mayoritas siswa kelas XI IPA di SMA Negeri 09 Kota Bengkulu termasuk dalam tingkat kategori interaksi sosial teman sebaya tinggi, akan tetapi masih ada siswa kelas XI IPA yang memiliki tingkat interaksi sosial teman sebaya pada kategori sedang. Oleh karena itu, alangkah lebih baik untuk memberikan layanan mengenai strategi untuk menumbuhkan dan meningkatkan interaksi sosial antar siswa atau teman sebaya yang nantinya akan mendukung siswa untuk memiliki kemampuan salah satunya kemampuan komunikasi interpersonal, dan tentunya akan membantu siswa terhindar dari penolakan sosial atau dalam hal ini penolakan kelompok teman sebaya. Guru BK juga sebaiknya dapat memberikan teladan kepada siswa agar mampu membangun interaksi dengan teman sebaya sehingga dapat diterima dengan baik oleh lingkungan sosialnya atau kelompok teman sebayanya, dengan memberikan beberapa pengalaman dalam menjalin hubungan dengan teman sebaya agar siswa menjadi terbiasa untuk berinteraksi dengan cara yang baik dan positif guna memperoleh penerimaan sosial.

\section{Daftar Pustaka}

Ahmadi, A. (2004). Psikologi Sosial. Jakarta: Rineka Cipta.

Berk, L. E. (2003). Child development, (6th ed.), MA: Allyn \& Bacon, Boston.

Walgito, B. (2003). Psikologi Sosial. Yogyakarta: Andi.

Chaplin, J.P. (1995). Kamus Lengkap Psikologi. Terj. Kartono Kartini. Jakarta: Grasindo Persada.

Drost, Ellen A. 2011. Validity and Reliability in Social Science Research. Education Researchand Perspectives,38,.(1)

Hurlock, E. B. (1980). Psikologi Perkembangan : Suatu Pendekatan Sepanjang Rentang Kehidupan. Jakarta : Penerbit Erlangga.

Santrock, J.W. (2007). Adolescense. Jakarta: Erlangga.

Yusuf, W. (2006). Psikologi Perkembangan Anak dan Remaja. Bandung: Remaja Rosdakarya.

Tirtarahardja, U. (1995). Pengantar Pendidikan. Jakarta: Depdiknas.

Santosa, S. (2004). Dinamika Kelompok. Jakarta: Bumi Aksara.

Sugiyono. (2009). Sikap Manusia: Teori dan Pengukurannya. Yogyakarta: Alfabeta.

W. A Gerungan. (2004). Psikologi Sosial. Bandung: Refika Aditama. 